\title{
Simultaneous 18F-FDG PET/MRI in tuberculous spondylitis: an independent method for assessing therapeutic response - case series
}

\author{
Ikchan Jeon ${ }^{1 *}$ (D) Eunjung Kong ${ }^{2}$ and Sang Woo Kim
}

\begin{abstract}
Background: ${ }^{18}$ F-fluorodeoxyglucose positron emission tomography (18F-FDG PET) shows great potential for diagnosis and assessing therapeutic response of tuberculous spondylitis. Tuberculous spondylitis required long-term antituberculosis (TB) medication therapy, and the optimal duration of therapy is controversial. There is still no clear way to tell when the anti-TB therapy can safely be discontinued.

Case presentation: Three patients with tuberculous spondylitis were evaluated for therapeutic response using 18F-FDG PET/magnetic resonance imaging (MRI). Clinical and hematological improvements were achieved after about 12 months of anti-TB medication therapy, and we considered whether to discontinue the therapy. There was no relapse during one year of follow-up after discontinuation of 12 months anti-TB medication based on the low maximum standardized uptake value ( $\left.S \cup V_{\text {max }}\right)$ of 1.83 in one patient. However, the other two patients continued further anti-TB medication therapy based on the high SUVmax of 4.14 and 7.02, which were suspected to indicate active residual lesions in the abscess or granulation tissues. Continuous TB was confirmed by the bacterial and histological examinations.

Conclusions: 18F-FDG PET/MRI has metabolic and anatomical advantages for assessing therapeutic response in TB spondylitis, and can be considered as a helpful independent and alternative method for determining the appropriate time to discontinue anti-TB medication.
\end{abstract}

Keywords: 18F-FDG PET, Tuberculous spondylitis, MRI, Therapeutic response

\section{Background}

Skeletal tuberculosis (TB) accounts for about $10-20 \%$ of extra-pulmonary TB, which comprises about $2 \%$ of total TB cases $[1,2]$. The most common form of skeletal TB is tuberculous spondylitis, which accounts for about $50 \%$ of all cases of skeletal TB [3]. In most cases, patients present pain as a main symptom. It is difficult to diagnose tuberculous spondylitis quickly because the symptoms are ambiguous. Tuberculous spondylitis commonly develops in the thoracolumbar region and is often accompanied by paravertebral or epidural abscesses [4].

\footnotetext{
* Correspondence: jicns@ynu.ac.kr

${ }^{1}$ Department of Neurosurgery, Yeungnam University Hospital, Yeungnam University College of Medicine, 170, Hyeonchung street, Nam-Gu, Daegu 42415, South Korea

Full list of author information is available at the end of the article
}

As of yet, there is no definitive guideline for treatment period and regimen, and also no clear assessing modality for the therapeutic response. Several studies have recently been reported on the role of ${ }^{18} \mathrm{~F}$-fluorodeoxyglucose positron emission tomography (18F-FDG PET) for diagnosis and assessing therapeutic response of tuberculous spondylitis $[5,6]$. However, the results of the 18F-FDG PET study associated with the actual timing of the discontinuation of anti-TB medication have not been confirmed. In this paper, three patients diagnosed with tuberculous spondylitis were evaluated for therapeutic response using simultaneous 18F-FDG PET/magnetic resonance imaging (PET/MRI) after 12 months of anti-TB medication therapy, and the associated clinical and radiological findings

(C) The Author(s). 2019 Open Access This article is distributed under the terms of the Creative Commons Attribution 4.0 International License (http://creativecommons.org/licenses/by/4.0/), which permits unrestricted use, distribution, and reproduction in any medium, provided you give appropriate credit to the original author(s) and the source, provide a link to the Creative Commons license, and indicate if changes were made. The Creative Commons Public Domain Dedication waiver (http://creativecommons.org/publicdomain/zero/1.0/) applies to the data made available in this article, unless otherwise stated. 
were analyzed and compared with the results of the existing literatures.

\section{Case presentation}

The first patient was a 43-year-old woman who had been suffering from back pain for about eight months. Infectious spondylitis on L2-3 with pre- and intravertebral abscesses was suspected from the MRI. The blood inflammatory indexes including C-reactive protein (CRP) and erythrocyte sedimentation rate (ESR) were increased by $1.57 \mathrm{mg} / \mathrm{dL}$ and $88 \mathrm{~mm} / \mathrm{h}$ from the initial $0.7 \mathrm{mg} / \mathrm{dL}$ and $30 \mathrm{~mm} / \mathrm{h}$, respectively (normal ranges are defined as $<0.5 \mathrm{mg} / \mathrm{dL}$ for CRP and $<20 \mathrm{~mm} / \mathrm{h}$ for ESR).

Following the results of a percutaneous needle biopsy, positive acid-fast bacilli (AFB), polymerase chain reaction (PCR), and caseation necrosis were detected and finally confirmed as tuberculous spondylitis. Although there was a medical history of pulmonary $\mathrm{TB}$, the sputum test showed negative result. A 12-month anti-TB medication therapy (daily isoniazid, rifampicin, pyrazinamide, and ethambutol for initial two-month, followed by a ten-month daily isoniazid, rifampicin, and ethambutol) was carried out without drug-susceptibility test (DST) under percutaneous biopsy due to favorable progress during the follow-up periods. PET/MRI at 12-month anti-TB medication therapy confirmed the loss of preand intra-vertebral abscesses with the decreased maximum standardized uptake value $\left(\mathrm{SUV}_{\max }\right.$, from 9.75 to 1.83) compared with $\mathrm{PET} / \mathrm{MRI}$ at 4-month anti-TB medication therapy (Fig. 1). Clinical, hematological (CRP and ESR were normalized at 4-months anti-TB medication therapy), and radiological tests showed no relapse during the one-year follow-up period.
The second patient was a 64-year-old woman who presented with about six months of posterior neck pain. The patient had no previous TB history. MRI showed infectious spondylitis on $\mathrm{C} 1-2$ with a totally eroded odontoid process and paravertebral abscesses. CRP showed nearly normal range at diagnosis and during the whole treatment periods. ESR was increased by $71 \mathrm{~mm} / \mathrm{h}$ and normalized at 3-month of anti-TB medication therapy. There was also the destruction of the left $\mathrm{C} 1$ and $\mathrm{C} 2$ bony structures with slight neck torticollis. Tuberculous spondylitis was confirmed with positive AFB, PCR, and caseation necrosis in an open biopsy. Surgical fixation and fusion were performed due to deterioration of the torticollis and instability of the cervical spine after 11.5-month of anti-TB medication therapy (daily isoniazid, rifampicin, pyrazinamide, and ethambutol for initial two-month, followed by a nine-months daily rifampicin and ethambutol due to resistance for isoniazid on the pus through the fistula of biopsy site). The territory of the lesion and SUV ${ }_{\max }$ (from 7.88 to 4.14) had decreased on the PET/MRI conducted just before surgery compared with PET/MRI at diagnosis (Fig. 2). However, positive AFB and PCR were detected from the granulation tissue of the surgical field, which resulted in additional anti-TB medication therapy (added levofloxacin to rifampicin and ethambutol).

The third patient is a 48-year-old woman who presented with about three months of back pain. CRP and ESR were $4.16 \mathrm{mg} / \mathrm{dL}$ and $115 \mathrm{~mm} / \mathrm{h}$, respectively (the indices have changed with the development and improvement of the fistula). Infectious spondylitis on T8-9 with paravertebral abscesses was confirmed on the MRI, and the result of the percutaneous needle biopsy showed

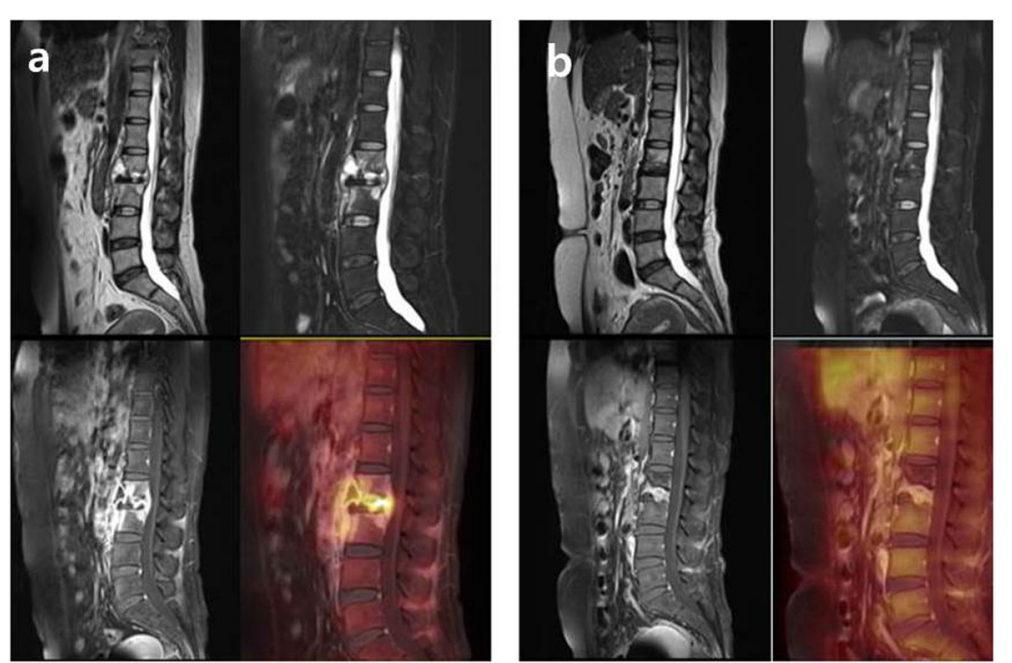

Fig. 1 The first patient's PET/MRI at 12-month anti-TB medication therapy (b) revealed the decreased bone marrow edema, pre- and intra-vertebral abscesses, paraspinal soft tissues, and SUV $\max$ (from 9.75 to 1.83) on L2-3 compared with PET/MRI at 4-month anti-TB medication therapy (a). There was no relapse during the one-year follow-up period after discontinuation of treatment 


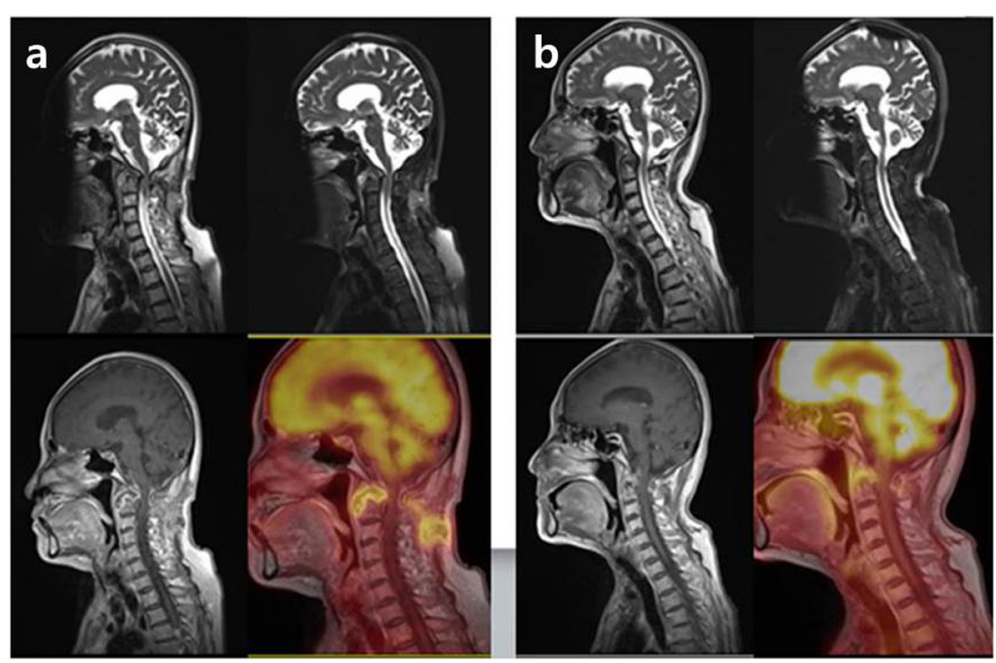

Fig. 2 The second patient's PET/MRI at 11.5-month anti-TB medication therapy (b) also revealed the decreased bone marrow edema with fatty

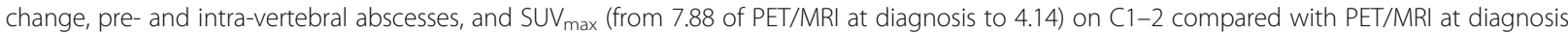
(a). However, positive AFB was detected from the granulation tissue of the surgical field, which resulted in additional anti-TB medication therapy

positive AFB, PCR, and caseation necrosis, finally confirmed as tuberculous spondylitis. At the same time, active pulmonary TB was also confirmed and anti-TB medication therapy (daily isoniazid, rifampicin, pyrazinamide, and ethambutol for initial two-month, followed by a ten-month daily isoniazid, rifampicin, and ethambutol) started. Afterwards, a fistula was formed along the biopsy tract between deep lesion and skin, which resulted in repeated wound debridement and closure. Discontinuation of anti-TB medication therapy was considered after 12-month, because there were improvements in the pulmonary lesions and overall clinical features with healing of fistula. However, PET/MRI at 12-month anti-TB medication therapy showed sustained abscesses around the paravertebral space with intra-abscess $\mathrm{SUV}_{\max }$ (from 6.67 to 7.02 ) even though decreased bone marrow edema and epidural abscess compared with PET/MRI at diagnosis (Fig. 3). After additional three months of antiTB medication, the leak of the tuberculous abscess through the fistula developed again. However, there was no drug resistance on DST of the pus through the repeated fistula.

Culture-based phenotypic DST and GenoType MTBDRplus (a reverse hybridization line probe assay, Hain Lifesciences, Nehren Germany) are performed on the samples positive for M. tuberculosis. Phenotypic

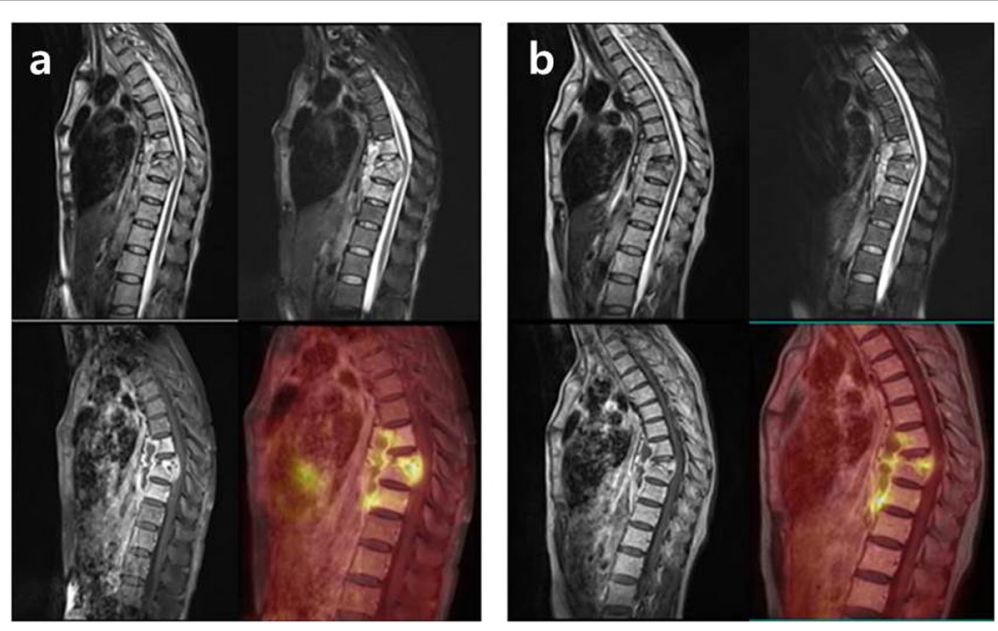

Fig. 3 The third patient's follow-up PET/MRI at 12-month anti-TB medication therapy (b) revealed sustained abscesses around the paravertebral space with intra-abscess SUV $\max$ (from 6.67 of PET/MRI at diagnosis to 7.02) even though decreased bone marrow edema and epidural abscess on T8-9 compared with PET/MRI at diagnosis (a). After additional three months of anti-TB medication, the leak of the tuberculous abscess through the fistula developed again 
DST will be determined by the absolute concentration method using Lowenstein-Jensen media as recommended by WHO [7] at the supranational reference laboratory. The drugs and their critical concentrations for resistance in the patients are as follows: isoniazid $0.2 \mu \mathrm{g} / \mathrm{mL}$, rifampin $40 \mu \mathrm{g} / \mathrm{mL}$, and ethambutol $2.0 \mu \mathrm{g} /$ $\mathrm{mL}$. Pyrazinamide susceptibility was determined by a pyrazinamide test [8].

Clinical characteristics and assessment for therapeutic response of the patients are summarized in Table 1.

\section{Discussion and conclusions}

The definitive diagnosis of tuberculous spondylitis is based on the result of cultural and pathological tests conducted in tissues collected from lesions. However, this method is only found to be positive at $50-75 \%$, and it is often necessary to conduct re-examination due to the high risk of false negatives [3, 9]. Sputum microscopy is available in pulmonary TB to determine treatment response, but it is not suitable in tuberculous spondylitis. Repeated biopsy and culture studies for detecting residual infectious lesion are neither reasonable nor perfect. Evaluation of therapeutic response in patients with tuberculous spondylitis TB usually indirectly depends on clinical and hematological features $[6,10,11]$.

An MRI is a highly sensitive test, and it can also be used to determine therapeutic response. Recent study has defined a significant regression in the epidural or paraspinal abscess/granulation tissues, marrow reconversion, and fatty reconstitution of the diseased bone as features of radiological healing [12]. Le Page et al. reported gradual conversion of initial vertebral body edemas to fatty signals in $40 \%$ of cases at six months and $75 \%$ at 12 months [13]. However, the radiological findings of healing are a process of long-term imaginal changes without regard to clinical symptoms. Marrow edema and vertebral involvement can worsen by six months, and changes can even be observed at up to 14 months [14, 15]. MRIs cannot differentiate active lesion from sterile residual ones, and many patients continue to present pain due to several reasons even after they have been healed of TB [12]. Additionally, MRIs cannot reveal when anti-TB medication therapy should be discontinued. In the first patient, specific MRI features, including decrease in marrow edema, abscess size, and paraspinal soft tissues associated with the healing

Table 1 Clinical characteristics and assessment for therapeutic response of the patients

\begin{tabular}{|c|c|c|c|}
\hline & Patient 1 & Patient 2 & Patient 3 \\
\hline \multicolumn{4}{|c|}{ Clinical characteristics } \\
\hline Age/Sex & 43/Women & 64/Women & 48/Women \\
\hline $\begin{array}{l}\text { Initial ESR } \\
(\mathrm{mm} / \mathrm{h}) / \\
\text { CRP }(\mathrm{mg} / \\
\mathrm{dL})\end{array}$ & $30 / 0.7$ & $51 / 0.536$ & $115 / 4.16$ \\
\hline Lesion & $\begin{array}{l}\text { Spondylitis on } L 2-3 \\
\text { Para- and intra-vertebral abscesses }\end{array}$ & $\begin{array}{l}\text { Spondylitis on } \mathrm{C} 1-2 \\
\text { Totally eroded odontoid process } \\
\text { Para-vertebral abscesses }\end{array}$ & $\begin{array}{l}\text { Spondylitis on T8-9 } \\
\text { Para-vertebral abscesses }\end{array}$ \\
\hline $\begin{array}{l}\text { Drug- } \\
\text { resistance }\end{array}$ & $(-)$ & $\begin{array}{l}\text { INH (+) on pus from fistula at biopsy } \\
\text { site }\end{array}$ & $(-)$ \\
\hline $\begin{array}{l}\text { HIV } \\
\text { serology }\end{array}$ & $(-)$ & $(-)$ & $(-)$ \\
\hline $\begin{array}{l}\text { SUV } \\
\text { max of } \\
\text { PET/MRI } 1\end{array}$ & 9.75 (at four-month of anti-TB medication) & 7.88 (at diagnosis) & 6.67 (at diagnosis) \\
\hline $\begin{array}{l}\text { Assessment } \\
\text { for } \\
\text { therapeutic } \\
\text { response }\end{array}$ & $\begin{array}{l}\text { Controlled } \\
\text { Discontinuation of anti-TB medication }\end{array}$ & $\begin{array}{l}\text { Uncontrolled } \\
\text { Continuation of anti-TB medication }\end{array}$ & $\begin{array}{l}\text { Uncontrolled } \\
\text { Continuation of anti-TB medication }\end{array}$ \\
\hline Timing & $\begin{array}{l}\text { 12-month after anti-TB medication (two- } \\
\text { month with INH, RFP, PZA, and EMB/ ten- } \\
\text { month with INH, RFP, and EMB) }\end{array}$ & $\begin{array}{l}\text { 11.5-month after anti-TB medication } \\
\text { (two-month with INH, RFP, PZA, and } \\
\text { EMB/ nine-month with RFP and EMB) }\end{array}$ & $\begin{array}{l}\text { 12-month after anti-TB medication } \\
\text { (two-month with INH, RFP, PZA, and EMB/ ten- } \\
\text { month with INH, RFP, and EMB) }\end{array}$ \\
\hline $\begin{array}{l}\text { Clinical } \\
\text { state }\end{array}$ & Improved & Improved & $\begin{array}{l}\text { Back pain } \\
\text { Recurrent development of fistula at biopsy site }\end{array}$ \\
\hline Evidence & Clinical improvement & AFB and PCR (+) on surgical biopsy & AFB and PCR (+) on pus from fistula \\
\hline $\begin{array}{l}\text { SUV } \\
\text { max of } \\
\text { PET/MRI } 2\end{array}$ & 1.83 & 4.14 & 7.02 \\
\hline
\end{tabular}

ESR: erythrocyte sedimentation rate, CRP: C-reactive protein, HIV: human immunodeficiency virus, SUV ${ }_{\text {max }}$ maximum standardized uptake value, $\mathrm{PET} / \mathrm{MRI}$ : ${ }^{18} \mathrm{~F}-$ fluorodeoxyglucose positron emission tomography/magnetic resonance imaging, TB: tuberculosis, INH: isoniazid, RFP: rifampin, PZA: pyrazinamide, EMB: ethambutol, AFB: acid-fast bacilli, PCR: polymerase chain reaction 
process were shown after 12 months of anti-TB medication therapy. In the second patient, however, TB existed continuously even though MRI features were related to the healing process.

For this reason, many efforts have been made to apply the 18F-FDG PET to evaluating therapeutic response, and several reports have recently been introduced. Using 18F-FDG PET measures the metabolic activity of the tissues in a non-invasive and semi-quantitative way, providing very accurate localization of the hypermetabolic activity. Active TB lesions are often proliferative lesions composed of epithelioid cells, Langerhans giant cells, and lymphocytes. These cells have high metabolisms of glucose and show a high uptake of FDG [16, 17]. Changes in FDG accumulation may be an important sign indicating the effect of anti-TB medication therapy. Metabolic responses may indicate therapeutic response and guide duration of antimicrobial therapy $[18,19]$.

From the results of the 18F-FDG PET in our patients, we expected the therapeutic response and completion of anti-TB medication therapy to accord with the $\mathrm{SUV}_{\max }$. The first patient, whose treatment had been completed, showed $\mathrm{SUV}_{\text {max }}$ of 1.83 , which is a very low as much as physiological FDG uptake in normal structures. In the second and third cases, $\mathrm{SUV}_{\max }$ of 4.14 and 7.02, respectively, were found to be the higher uptake of SUV$\max$ continuously within the paravertebral abscesses. These are judged to be a more accurate and consistent indication of the state of the TB lesion than MRI. The lesion presenting higher uptake of FDG can be explained by the overpopulation of the inflammatory cells described above, which are consistently present within the infected structures such as abscesses or vertebrae.

The optimal duration of anti-TB medication therapy is controversial. The Medical Research Council (MRC) advocates short-course chemotherapy (six months) for uncomplicated spinal TB [20]. However, Cormican et al. reported that mean duration of treatment was 13 months (range: 9-24 months) [21]. The region of the authors of this paper shows higher incidence and prevalence of drug resistance in TB. Therefore, the determination of the treatment duration should consider the regional characteristics and severity of the lesion, and discontinuation of anti-TB medication therapy should be prudent and conservative. When a relapse occurs, it usually happens within 12 months after the completion of therapy, indicating that the disease was incompletely treated [22].

There is a difference in the degree of FDG uptake depending on the presence of TB even after 12 months of anti-TB medication therapy. Especially in the third patient with active $\mathrm{TB}$, the $\mathrm{SUV}_{\max }$ (7.02) was kept very high regardless of the treatment duration, which meant that active TB was sustained and eventually led to abscess discharge through fistula again. However, as with the second patient, it was difficult to determine whether anti-TB medication should be discontinued, considering the healing process of the overall lesions and constantly reduced $\mathrm{SUV}_{\max }$ (4.14). Successfully treated pyogenic spondylitis sometimes shows sustained high level of FDG uptake of 18F-FDG PET following weeks of antibiotics treatment, which can be explained by severe tissue damage and its healing process. Unlike pyogenic spondylitis, tuberculous spondylitis takes more time to sterilize than pyogenic spondylitis. The damaged tissues are also expected to be restored over long periods of sterilizing $\mathrm{TB}$, resulting in lower FDG uptake $\left(\mathrm{SUV}_{\max }\right.$ 1.83 of the first patient) at the end of treatment than that of pyogenic spondylitis. Given this, the second patient can be determined to have a continuous TB and require further anti-TB medication therapy.

We think that 18F-FDG PET/MRI can be considered as a helpful independent and alternative method for determining the appropriate time to discontinue anti-TB medication. However, 18F-FDG PET/MRI is still very expensive examination and has low accessibility, which is limited to apply generally in the patients with TB spondylitis. Further studies with more patients are required to demonstrate our results and to overcome the limitations.

\section{Abbreviations}

18F-FDG PET: Fluorine-18 fluorodeoxyglucose positron emission tomography: AFB: Acid-fast bacilli; PCR: Polymerase chain reaction; PET/MRI: Fluorine-18 fluorodeoxyglucose positron emission tomography /magnetic resonance imaging; SUVmax: Maximum standardized uptake value; TB: Tuberculosis

\section{Acknowledgements}

Not applicable

\section{Authors' contributions}

IJ was the principal clinician who planned the entire evaluation and procedure. EK investigated and treated the aspects of nuclear medicine. SWK was advisor for the clinical procedures and planning study design. All authors have read and approved the manuscript.

\section{Funding}

This work was supported by the 2017 Yeungnam University Research Grant (Grant number: 217A580029), which involved in the design of the study and collection, analysis, and interpretation of data as well as the manuscript.

\section{Availability of data and materials}

The datasets used and/or analyzed during the current study are available from the corresponding authors on the reasonable request.

\section{Ethics approval and consent to participate}

Voluntary written informed consent was obtained prior to the study from the patients under approval of the Institutional Review Board, Yeungnam University Hospital (No. 2017-07-006).

\section{Consent for publication}

Written informed consent was obtained from the patient or patient's family for publication of this case series and any accompanying images. A copy of the written consent is available for review by the Editor of this journal.

Competing interests

The authors declare that they have no competing interests. 


\section{Author details}

${ }^{1}$ Department of Neurosurgery, Yeungnam University Hospital, Yeungnam University College of Medicine, 170, Hyeonchung street, Nam-Gu, Daegu 42415, South Korea. ${ }^{2}$ Department of Nuclear Medicine, Yeungnam University Hospital, Yeungnam University College of Medicine, Daegu, South Korea.

Received: 27 March 2019 Accepted: 12 September 2019

Published online: 15 October 2019

\section{References}

1. Peto HM, Pratt RH, Harrington TA, LoBue PA, Armstrong LR. Epidemiology of extrapulmonary tuberculosis in the United States, 1993-2006. Clin Infect Dis. 2009:49(9):1350-7.

2. Teo HE, Peh WC. Skeletal tuberculosis in children. Pediatr Radiol. 2004; 34(11):853-60

3. Kimizuka Y, Ishii M, Murakami K, Ishioka K, Yagi K, Ishii K, Watanabe K, Soejima K, Betsuyaku T, Hasegawa N. A case of skeletal tuberculosis and psoas abscess: disease activity evaluated using (18) F-fluorodeoxyglucose positron emission tomography-computed tomography. BMC Med Imaging. 2013;13:37.

4. Harrigan RA, Kauffman FH, Love MB. Tuberculous psoas abscess. J Emerg Med. 1995;13(4):493-8.

5. Treglia G, Taralli S, Calcagni ML, Maggi F, Giordano A, Bonomo L. Is there a role for fluorine 18 fluorodeoxyglucose-positron emission tomography and positron emission tomography/computed tomography in evaluating patients with mycobacteriosis? A systematic review. J Comput Assist Tomogr. 2011;35(3):387-93.

6. Tian G, Xiao Y, Chen B, Xia J, Guan H, Deng Q. FDG PET/CT for therapeutic response monitoring in multi-site non-respiratory tuberculosis. Acta Radiol. 2010;51(9):1002-6.

7. . In: Companion Handbook to the WHO Guidelines for the Programmatic Management of Drug-Resistant Tuberculosis. edn. Geneva; 2014.

8. Wayne LG. Simple pyrazinamidase and urease tests for routine identification of mycobacteria. Am Rev Respir Dis. 1974;109(1):147-51.

9. Small PM, Hopewell PC, Singh SP, Paz A, Parsonnet J, Ruston DC, Schecter GF, Daley CL, Schoolnik GK. The epidemiology of tuberculosis in San Francisco. A population-based study using conventional and molecular methods. N Engl J Med. 1994;330(24):1703-9.

10. Wallis RS, Doherty TM, Onyebujoh P, Vahedi M, Laang H, Olesen O, Parida S, Zumla A. Biomarkers for tuberculosis disease activity, cure, and relapse. Lancet Infect Dis. 2009:9(3):162-72.

11. Walzl G, Ronacher K, Djoba Siawaya JF, Dockrell HM. Biomarkers for TB treatment response: challenges and future strategies. J Inf Secur. 2008; 57(2):103-9.

12. Kedhi E, Fabris E, van der Ent M, Buszman P, von Birgelen C, Roolvink V, Zurakowski A, Schotborgh CE, Hoorntje JCA, Eek CH, et al. Six months versus 12 months dual antiplatelet therapy after drug-eluting stent implantation in ST-elevation myocardial infarction (DAPT-STEMI): randomised, multicentre, non-inferiority trial. BMJ. 2018;363:k3793.

13. Le Page L, Feydy A, Rillardon L, Dufour V, Le Henanff A, Tubach F, Belmatoug N, Zarrouk V, Guigui P, Fantin B. Spinal tuberculosis: a longitudinal study with clinical, laboratory, and imaging outcomes. Semin Arthritis Rheum. 2006;36(2):124-9.

14. Singh R, Magu NK, Rohilla RK. Clinicoradiologic profile of involvement and healing in tuberculosis of the spine. Ann Med Health Sci Res. 2016; 6(5):311-27.

15. Jain AK, Jena A, Dhammi IK. Correlation of clinical course with magnetic resonance imaging in tuberculous myelopathy. Neurol India. 2000;48(2): 132-9.

16. Metser U, Even-Sapir E. Increased (18)F-fluorodeoxyglucose uptake in benign, nonphysiologic lesions found on whole-body positron emission tomography/computed tomography (PET/CT): accumulated data from four years of experience with PET/CT. Semin Nucl Med. 2007;37(3):206-22.

17. Sanabe N, Ikematsu Y, Nishiwaki Y, Kida H, Murohisa G, Ozawa T, Hasegawa S, Okawada T, Toritsuka T, Waki S. Pancreatic tuberculosis. J Hepato-BiliaryPancreat Surg. 2002;9(4):515-8.

18. Hofmeyr A, Lau WF, Slavin MA. Mycobacterium tuberculosis infection in patients with cancer, the role of 18-fluorodeoxyglucose positron emission tomography for diagnosis and monitoring treatment response. Tuberculosis (Edinb). 2007:87(5):459-63.
19. Park IN, Ryu JS, Shim TS. Evaluation of therapeutic response of tuberculoma using F-18 FDG positron emission tomography. Clin Nuc Med. 2008;33(1):1-3.

20. Five-year assessment of controlled trials of short-course chemotherapy regimens of 6,9 or 18 months' duration for spinal tuberculosis in patients ambulatory from the start or undergoing radical surgery. Fourteenth report of the Medical Research Council Working Party on Tuberculosis of the Spine. Int Orthop 1999, 23(2):73-81.

21. Cormican L, Hammal R, Messenger J, Milburn HJ. Current difficulties in the diagnosis and management of spinal tuberculosis. Postgrad Med J. 2006; 82(963):46-51.

22. Nunn AJ, Phillips PP, Mitchison DA. Timing of relapse in short-course chemotherapy trials for tuberculosis. Int J Tuberc Lung Dis. 2010;14(2):241-2.

\section{Publisher's Note}

Springer Nature remains neutral with regard to jurisdictional claims in published maps and institutional affiliations.
Ready to submit your research? Choose BMC and benefit from:

- fast, convenient online submission

- thorough peer review by experienced researchers in your field

- rapid publication on acceptance

- support for research data, including large and complex data types

- gold Open Access which fosters wider collaboration and increased citations

- maximum visibility for your research: over $100 \mathrm{M}$ website views per year

At BMC, research is always in progress.

Learn more biomedcentral.com/submissions 